\title{
Presentació
}

Saber (del) plural

\author{
Begonya Sáez Tajafuerce \\ Universitat Autònoma de Barcelona \\ begonya.saez@uab.cat
}

L'any 1993, ara fa un quart de segle, Linda Alcoff i Elizabeth Potter editen Feminist Epistemologies (Nova York i Londres: Routledge). Ja en el pròleg del llibre, titulat "When Feminisms intersect Epistemology", assenyalen sense embuts quin és el compromís polític que les feministes assumeixen en relació amb l'epistemologia:

For feminists, the purpose of epistemology is not only to satisfy intellectual curiosity, but also to contribute to an emancipatory goal: the expansion of democracy in the production of knowledge. This goal requires that our epistemologies make it possible to see how knowledge is authorized and who is empowered by it. It follows that feminist epistemologies should be self-reflexive, able to reveal their own social grounds, a revelation made all the more urgent because academic feminists are in a contradictory social position, seeking fundamental changes in the very institutions that empower us to speak and work. (Alcoff i Potter, 1993: 13-14)

És important no perdre de vista que, aquí, l'afany d'emancipació que assumeix el feminisme s'articula en plural. Alcoff i Potter parlen d'"epistemologies» que remeten a «sabers». Què indica aquest plural? Per què no epistemologia? Per què no saber? Hi ha diverses raons que justifiquen la reivindicació del plural en relació amb aquest compromís polític del feminisme. La primera és que, d'acord encara amb les editores de Feminist Epistemologies, «el terme no té un únic referent i [...] tal vegada no en tingui mai un de sol». Aquesta indeterminació constitutiva comporta un repte per a la "premissa que un compte retut del saber en termes generals és possible, [és a dir] un compte retut que ignora el context social i l'establiment del subjecte del coneixement. Aquesta és la premissa que les epistemologies feministes han qüestionat». Des del feminisme es qüestiona la indiferència dels comptes retuts que es duen a terme en nom dels sabers dominants, és a dir, dels sabers produïts i validats per subjectes autoritzats i instal-lats en espais de dominació política, social i econòmica, en oposició a sabers que podríem anomenar, d'acord amb Alcoff i Potter, «subalterns» (cfr. Alcoff i Potter, 1993: 1). 
Alhora, la necessitat de parlar d'epistemologies i de sabers feministes en plural respon al caràcter de les incursions que es duen a terme en clau teòrica des dels marges, a fi de conformar espais de sabers altres que no se situen al centre i que no se situen tampoc a la pura idealitat abstracta, aval i seu del que és general o universal, sinó que atén sobretot la realitat material aspirant de la particularitat o de la singularitat.

També cal parlar d'epistemologies feministes en plural, perquè la tasca crítica que comporta tot esforç feminista s'estén no tan sols més enllà dels límits de la demarcació teòrica hegemònica, sinó fins i tot més enllà dels límits de la demarcació ideològica disciplinària, de manera que esdevé possible una nova i diferent conformació d'aquests límits com a tals, els quals esdevenen, aleshores, espais fronterers que donen lloc a sabers fronterers (abans anomenats «sabers fonamentals» en oposició a sabers aplicats), que es conformen una vegada i una altra en relació mútua i parant esment a les condicions materials que els determinen.

Cal insistir, però, amb Alcoff i Potter, que l'impacte del discurs feminista en el discurs del saber es justifica en la mateixa mesura pel caràcter reflexiu del qüestionament. L'efecte immediat d'aquest qüestionament és que, així com no hi ha un sol discurs per al saber, tampoc no hi ha un sol discurs per al feminisme $i$, en conseqüència, tractem amb feminismes, en plural. La veu del feminisme és una veu (del) plural.

Reivindicar per al feminisme una veu (del) plural vol dir, aquí, situar-lo en la diferència i fer del pensament feminista un pensament que troba en la diferència el seu lloc d'enunciació. D'acord amb Karen Barad i amb Donna Haraway, dir(-se) en la diferència comporta dir(-se) en la difracció permanent. Comporta dir(-se) en una desviació permanent respecte del subjecte i de l'objecte d'enunciació que afecta el sentit que en pot resultar, tot disseminant-lo en una heterocausalitat que és i que roman radicalment contingent. Aquí s'afirma la contingència dels sabers.

Tanmateix, no per a totes les epistemologies feministes opera la contingència ni tampoc, quan hi opera, ho fa de la mateixa manera. En un article de $1999^{1}$, Stella Vilarmea Requejo recorda la classificació que, en el context del pensament nord-americà, regeix encara les epistemologies feministes i permet de situar-les en el panorama teòric vigent. Segons aquesta classificació, hom hi considera tres corrents principals:

1. L'empirisme feminista, que procura realitzar una depuració del discurs científic i sobre la ciència del seu biaix patriarcal, encara que sense sotmetre a

1. Stella Vilarmea Requejo (1999), "Conocimientos situados y estrategias feministas», Reden: Revista Española de Estudios Norteamericanos, 17-18, [219]-235, ISSN 1131-9674. La presentació que fa l'autora de l'article del tercer corrent de les epistemologies feministes divergeix de la presentació que se n'ofereix aquí, en la mesura en què aquí es té en compte un dels elements que determinen la posició que cada subjecte adopta com a ésser de llenguatge i que apunta a una dimensió que és suplementària de la voluntat i/o de la consciència, és a dir, la dimensió del desig i del gaudi. 
revisió crítica els conceptes forts, metafísics, de veritat, objectivitat i universalitat, veritables pilars de l'epistemologia clàssica. Helen Longino, Evelyn F. Keller o Lorraine Code són noms destacats d'aquest corrent.

2. Les autores que s'adscriuen al corrent del saber situat, al seu torn, Sandra Harding i Nancy Hartsock com a precursores, i Donna Haraway de manera extensa i marcadament interdisciplinària, interseccional (que atén els diversos factors que determinen el saber a més del gènere, com ara la raça i la classe, encara que també l'edat, el bagatge cultural o l'elecció sexual) i posthumanista (que atén, en un interès crític de l'antropocentrisme, unes altres espècies a banda de la humana i que té en compte la relació entre elles), reconeixen la determinació de tot saber per part de les condicions materials i immaterials en virtut de les qual es genera, i reconeixen, també, que aquest saber s'enuncia sempre, aleshores, en una perspectiva i en un context concrets als quals es limita i se circumscriu, encara que aquest doble reconeixement no comporta cap renúncia a l'objectivitat.

3. La filiació a la postmodernitat permet delimitar el tercer corrent de les epistemologies feministes. Aquesta filiació s'articula des d'una consideració dels sabers com a llocs discursius en què el subjecte d'enunciació s'ubica en tant que travessat pel llenguatge, és a dir, en tant que determinat també pel desig i pel gaudi, com diria Elizabeth Grosz. En aquest sentit, els sabers atenen no ja les seves condicions particulars, sinó també les seves condicions singulars, és a dir, les condicions que són les de cada subjecte en la seva singularitat. Aquestes condicions excedeixen el discurs i constitueixen, doncs, un excés també per al saber. Aquí s'afirma la singularitat dels sabers.

La cartografia traçada mitjançant la classificació recuperada mostra una certa progressió relativa als reptes que, en relació amb l'epistemologia, ha anat assumint el feminisme. L'assumpció d'aquests reptes, en tant que polítics, convé insistir-hi, afecta el feminisme de tal manera que avui cal parlar tant d'epistemologies feministes com de feminismes. No es tracta de fer manifesta ni tan sols de reivindicar la pluralitat sense més ni més, sinó, com deia abans, de situar el saber en la diferència. I, en concret, en la diferència sexual. És a dir, en la diferència que eludeix la dialèctica, en la diferència irreductible, que sembla que és la via per articular una crítica a/efectiva de la lògica binària i de l'economia excloent del discurs. I aquesta via fa de la diferència no un objecte, ni un mer tema, ni una insígnia, ni, encara menys, una bandera; tampoc no en fa quelcom que hom blasmi ni que hom reclami, sinó que en fa el modus operandi del discurs i, així, del saber. Disposats a la contingència i a la singularitat, el discurs i el saber fan diferència. I això comporta, en primer lloc, que el discurs i el saber es disposen al cos com a subjecte i com a lloc d'enunciació alhora.

L'objectiu d'aquest volum de la revista ENRAHONAR, dedicat a les epistemologies feministes, rau a palesar, en primer lloc, la naturalesa dels sabers dominants per tal de posar-la en relació amb la naturalesa dels sabers feministes, la lògica (im)pròpia dels quals convé explicitar, i també rau a palesar, en segon lloc, les condicions i les conseqüències del desplaçament que comporta atorgar 
al cos l'estatut de subjecte, primerament de coneixement i, tot seguit, polític. S'assumeix, així, el repte encara viu per als feminismes, inclosa la teoria de gènere i queer, d'articular propostes per fer avinent una transformació individual i col.lectiva mitjançant la generació d'espais altres per a sabers altres, en els plecs i en els intersticis de les disciplines, tot començant pel subjecte de saber altre per excel.lència, que és el cos sexuat. Aquesta remissió radical a l'alteritat permet de desplaçar la identitat com a principi regulador de teories i pràctiques $i$, aleshores, també com a principi normatiu que suscita i que corrobora un saber - $\mathrm{i}$ un fer- jeràrquic.

Elizabeth Grosz apuntava en el seu article «Bodies and Knowledges: Feminism and the Crisis of Reason", inclòs a Feminist Epistemologies, la necessitat epistemològica i política de prendre en consideració el que ella anomena «sexualització explícita dels sabers", per tal de fer manifest, d'entrada, que no hi ha saber neutre, contràriament a com se suposa des d'un paradigma epistemològic $i$, alhora, polític, que s'articula segons els paràmetres de la racionalitat instrumental i/o il.lustrada tout court. Aquí es tracta, per tant, d'atendre la lògica d'una raó altra que podem anomenar «raó de cos».

Els sis articles que integren aquest monogràfic paren esment en aquesta raó de cos. S'hi aboquen. La despleguen. I, d'aquest manera, posen en obra, des de llocs i referents teòrics diferents, és a dir, atents a la diferència, la desestabilització dels sabers hegemònics sense reclamar, en canvi, cap posició hegemònica per a si. Els sabers dels quals els articles són testimoni aquí procuren espais altres dels espais que acullen i que susciten una disputa pel poder i, sobretot, es volen aliens a la relació de complicitat entre saber i poder que Foucault tan detalladament va reportar. Els epígrafs que acompanyen els articles fan manifest el signe de cadascun d'aquests espais altres i no corresponen a cap mena de classificació, és a dir, a cap mena d'ordenació jeràrquica. Tampoc no es tracta d'una mostra exhaustiva ni exemplar. Hom hi hauria pogut incloure uns altres sabers altres, com ara locals, populars, mestissos, emergents, creuats, residuals, del Sud, etc. Allò que tots tenen en comú és que són sabers nascuts del cos, fills de la contingència. Són sabers singulars i, per això, (im)propis. I són sabers que han fet seves les aspiracions polítiques dels feminismes i que apunten a la transformació social i econòmica, individual i col-lectiva, mitjançant un exercici crític d'autoreflexió que ha de donar lloc a la construcció en plural d'una genealogia feminista del saber en permanent remissió a la història $i$ a les condicions materials del pensament, de les seves estructures, de la seva lògica, dels seus fonaments, així com de la seva condició vulnerable, en tant que àmbit de producció de coneixement que es veu afectat també per les astúcies i els embats de la ideologia.

Estic d'acord amb Teresa De Lauretis que aquest exercici crític d'autoreflexió condueix, paradoxalment, a una mena d'exili permanent, en la mesura en què obliga a renunciar a la «llar», a una certa llar, si més no, que hom abandona «físicament, emocionalment, lingüísticament i epistemològica per un altre lloc que és desconegut, arriscat, que no és altre només emocionalment, sinó també conceptualment, per un lloc discursiu des del qual parlar o pensar és 
temptatiu, insegur i sense garanties» ${ }^{2}$. Els sabers altres són sabers que renuncien a instal.lar-se en la certesa on se sosté el saber que fa binomi amb el poder. Per això comporten un exercici de desidentificació permanent que és la clau de la seva capacitat transformadora i que consisteix a dur a terme un desplaçament "personal i conceptual» del qual parla De Lauretis i que afecta també la pròpia posició, és a dir, la posició de cadascú i de cadascuna en el si del feminisme. Aquí hi ha sabers en moviment que posen en moviment subjectes, idees i realitats.

En efecte, aquí hom se situa en el saber, hom hi està, "com una estrangera», diríem amb Gilles Deleuze i Félix Guattari quan parlen de Kafka en el capítol "Qu'est-ce qu'une littérature mineure?» del llibre Pour une littérature mineure (1975). Segons els autors, són tres les característiques de la literatura menor en la ploma de Kafka: la desterritorialització de la llengua, el seu caràcter polític i el seu valor col-lectiu. Tot i que sense afany de calcar aquesta proposta com a pauta de caracterització dels sabers altres dels quals són testimoni els articles inclosos en aquesta monografia dedicada a les epistemologies feministes, i encara menys de manera extensa, sembla escaient parlar-ne com a sabers menors. Ho són, de menors, perquè, de fet, comporten una desterritorialització del discurs propi del saber territorial, en el sentit en què el posen en evidència allí on ens resulta familiar per tal com ha format i forma encara el nostre pensament i per tal com hi reïxen conceptes i lògiques que donen compte de tot. La qüestió del tot és fonamental per comprendre el repte polític que assumeixen els feminismes amb la generació de sabers altres. Es tracta de desterritorialitzar el discurs del tot que troba el seu fonament i que a la vegada corrobora la creença que sobre el món i la vida que ens envolten tot es pot dir, tot es pot llegir i tot es pot conèixer. I es tracta de fer-ho per la força d'un impossible. El referent que els sabers altres troben en les condicions materials de l'existència $i$, en particular, en el cos sexuat, dona compte d'aquest impossible per tal com el constitueix i, així, dona compte del límit constitutiu de tot saber, del saber del tot. Tots i cadascun dels articles inclosos en aquest volum d'EnRAHONAR en donen compte.

La literatura és un impossible per a Kafka, perquè és impossible «no escriure, no escriure en alemany, escriure altrament» (Deleuze i Guattari, 1978: 28) ${ }^{3}$. Els sabers altres són també sabers d'un impossible, perquè és impossible no dir i no fer el desplegament temptatiu d'una lògica (del) plural, segons la qual qualsevol idea o teoria enunciada de manera individual «esdevé una acció col-lectiva i allò que hom diu o fa és necessàriament polític, fins i tot si la resta no hi està d'acord» (Deleuze i Guattari, 1978: 30). Que l'enunciació és collectiva vol dir que «l'enunciat no remet a un subjecte de l'enunciat que en seria

2. Teresa De Lauretis (1993), «Sujetos excéntricos: La teoría feminista y la conciencia històrica», aparegut originàriament a María C. CANGiamo i Lindsay DuBois (comp.), De mujer a género, teoría, interpretación y práctica feministas en las ciencias sociales, Buenos Aires, Centro Editor de América Latina, 73-113. La traducció al català és meva.

3. Gilles Deleuze i Félix Guattari (1978), «¿Qué es una literatura menor?», a: Por una literatura menor, Mèxic, Ediciones Era. La traducció al català és meva. 
una causa ni a un subjecte de l'enunciat que en seria l'efecte» (Deleuze i Guattari, 1978: 30). L'enunciació és una forma d'agencement, és a dir, de generació col-lectiva d'espais crítics que acullen sabers altres que convoquen a la transformació. Aquí rau la veritable força revolucionària de la literatura segons Kafka i dels sabers altres, convé afegir-hi. No rau en la ideologia, sinó en el compromís (del) plural amb l'impossible.

Es per això que, en darrera instància, «menor» no caracteritza les literatures, no caracteritza cap pràctica discursiva, doncs, tampoc. En canvi, «menor» qualifica, segons Deleuze i Guattari, «les condicions revolucionàries de qualsevol literatura en el si de l'anomenada major (o establerta)» (Deleuze i Guattari, 1978: 31). És a dir, a tenor del paral-lelisme proposat, «menor» no diu dels sabers, sinó més aviat de les condicions revolucionàries de qualsevol saber en tant que saber altre en el si del saber establert. Diu de la possibilitat de dir i fer l'impossible i diu del compromís (del) plural amb aquesta possibilitat. I diu, sobretot, aquí, de l'afany compartit en tots i cadascun dels sis articles inclosos en aquest volum. Tots i cadascun conviden obertament i des de la consistència que atorga l'experiència viscuda a posar a prova la posició pròpia en el saber sense témer que aquesta esdevingui aliena, i no dubten «a trobar el propi punt de subdesenvolupament, el propi argot, el propi tercer món, el propi desert» (Deleuze i Guattari, 1978: 31), ni a exposar-s'hi. Tots i cadascun diuen del saber (del) plural.

\section{Referències bibliogràfiques}

Alcoff, Linda i Potter, Elizabeth (1993). Feminist Epistemologies. Nova York i Londres: Routledge.

De Lauretis, Teresa (1993). «Sujetos excéntricos: La teoría feminista y la conciencia històrica». A: María C. Cangiamo i Lindsay DuBois (comp.). De mujer a género, teoría, interpretación y práctica feministas en las ciencias sociales. Buenos Aires: Centro Editor de América Latina, 73-113.

Deleuze, Gilles i Guattari, Félix (1975). «Qu'est-ce qu'une littérature mineure?». A: Pour une littérature mineure. París: Éditions du Seuil.

Grosz, Elizabeth (1993). «Bodies and Knowledges: Feminism and the Crisis of Reason». A: Feminist Epistemologies. Nova York i Londres: Routledge.

Vilarmea Requejo, Stella (1999). "Conocimientos situados y estrategias feministas». Reden: Revista Española de Estudios Norteamericanos, 17-18, [219]-235. 